\title{
Design of Polymeric Nanofiber Gauze Mask to Prevent Inhaling PM2.5 Particles from Haze Pollution
}

\author{
Xingzhou Li ${ }^{1}$ and Yan Gong ${ }^{2}$ \\ ${ }^{1}$ Beijing No. 35 High School, Beijing 100032, China \\ ${ }^{2}$ Department of Materials Science and Engineering, Beijing Institute of Fashion Technology, Beijing 100029, China \\ Correspondence should be addressed to Yan Gong; clygy@bift.edu.cn
}

Received 23 February 2015; Accepted 1 April 2015

Academic Editor: Qichen Wang

Copyright (C) $2015 \mathrm{X}$. Li and Y. Gong. This is an open access article distributed under the Creative Commons Attribution License, which permits unrestricted use, distribution, and reproduction in any medium, provided the original work is properly cited.

\begin{abstract}
Recently, PM2.5 (particulate matter with diameter of 2.5 micron or less) has become a major health hazard from the polluted air in many cities in China. The regular gauze masks are used to prevent inhaling the PM2.5 fine particles; however, those masks are not able to filter out the PM2.5 because of the large porosity of the mask materials. Some well-prevented masks usually have poor breathability, which increases other health risks. In this study, a polysulfone based nanofiber for mask filtration material was synthesized by electrospinning. That nanofiber mask material was characterized by SEM, air permeability test, and PM2.5 trapping experiment. The results indicate that nanofiber mask material can efficiently filter out the PM2.5 particles and simultaneously preserve a good breathability. We attribute such improvement to the nanoscaled fibers, having the same porosity as that of regular gauze mask but with extremely reduced local interfiber space.
\end{abstract}

\section{Introduction}

PM2.5 (particulate matter with diameter of 2.5 micron or less) in polluted air can directly go through the lung alveolar to cause many diseases including asthma [1]. Recently, many Chinese cities are covered by haze air. Figure 1 showed the polluted air in Beijing. The heavy metals adhered on PM2.5 particles may even lead to severe chronic health problems such as cancer after long-term exposure under the particles contained environment [2].

In order to prevent inhaling PM2.5 in haze, people wear regular gauze masks. Most of those masks are made of non-woven fabric, activated carbon, or cotton which has fiber diameter of several micrometers [3]. They have significant shortcoming of poor PM2.5 rejection and low air permeability [4].

In this paper, a novel polymeric nanofiber masks were synthesized by electrospinning. Such masks based on nanofibers are expected to well prevent the PM2.5 particles and maintain a good air permeability. These nanofibers can be potentially developed to high efficiency and low cost mask product.

\section{Materials and Methods}

2.1. Experiment Materials. Polysulfone, acetone, polyethylene oxide, and dimethyl acetamide were purchased from Beijing Chemical Factory, China. Medical clinic masks, medical operating room masks, ITO PM2.5 masks, N95 respirator, and R95 masks were purchased from Tianjin Youkang medical and health care products factory. All chemicals were of analytical grade and were used without further purification.

2.2. Procedure for Electrospinning. Polysulfone solution was prepared at a concentration of $18 \mathrm{wt} \%$ by dissolving in DMAc/acetone $(9: 1)$ with vigorous stirring. The prepared solution was kept overnight without stirring under room temperature to remove air bubbles. For the electrospinning, the $18 \mathrm{wt} \%$ polysulfone solutions were filled into a syringe with a metal needle connected with a high-voltage power supply (Tianjin Dongwen High Voltage Co., China). The voltage is $13 \mathrm{KV}$ and the distance between the needle and the aluminium foil is $13 \mathrm{~cm}$. The polymer solution was fed at a constant rate of $0.4 \mathrm{~mL} / \mathrm{h}$ by using a syringe pump. 
TABLE 1: Electrospinning conditions.

\begin{tabular}{|c|c|c|c|c|c|c|}
\hline Polymer & Solvent & Humidity & Flow rate & Voltage & Distance & Time \\
\hline $\begin{array}{l}\text { Polysulfone } \\
1.8 \mathrm{~g} / \text { polyethylene } \\
\text { oxide } 0.018 \mathrm{~g}\end{array}$ & $\begin{array}{l}\text { Dimethylacetamide } \\
9 \mathrm{~mL} / \text { acetone } 1 \mathrm{~mL}\end{array}$ & $53 \%$ & $0.4 \mathrm{~mL} / \mathrm{h}$ & $13 \mathrm{kV}$ & $13 \mathrm{~cm}$ & $\begin{array}{l}15 \mathrm{~min} \\
30 \mathrm{~min} \\
60 \mathrm{~min}\end{array}$ \\
\hline
\end{tabular}

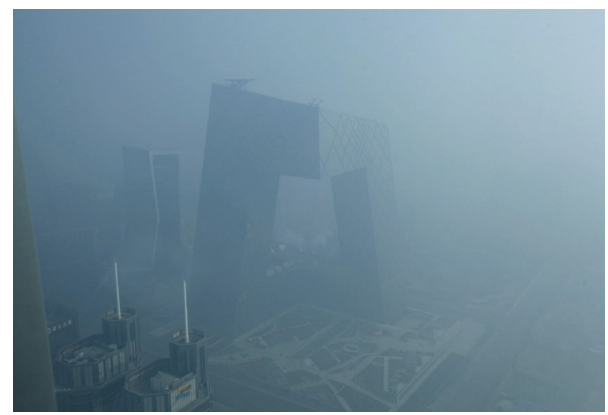

Figure 1: Typical haze in Beijing.

The nanofibers were collected on the surface of a non-woven $\mathrm{PP}$ on the grounded aluminium foil. The collective time of nanofibers was 15,30 , and $60 \mathrm{~min}$. More detailed information was shown in Table 1.

2.3. Morphology Observation. The membranes were dried in vacuo and sputtered gold before observation. The morphology of nanofiber membranes was imaged by scanning electron microscopy (SEM, Hitachi T-1000, Japan).

2.4. Permeability Simulation Test. Permeability simulation test device mainly includes a pump, a pressure differential gauge, a meter, and bronchus. The nanofiber matts and the commercial masks as control group were clamped by a wellsealed testing chamber, which was connected with a syringe at top, install a pressure meter at the side exit. The bottom side of the chamber was open to the ambient air. Counterweights were placed on the syringe to adjust the pressure inside the testing chamber. The resulting pressure above the nanofiber matts was measured by the pressure meter.

2.5. Intercept Rate Test. Intercept experimental equipment was conducted in a nuclear particle counter (Model of CPC 3772 made in TSI Company). That counter can measure the concentration of particles (diameter between 10 and $2500 \mathrm{~nm}$ ) in the air. The particle concentration in air represented the PM2.5 intercept rate of the filtration material.

2.6. Data Analysis. All data were means \pm SD from three independent experiments. Comparisons between multiple groups were performed with the ANOVA test by SPSS. $P$ values less than 0.05 were considered statistically significant.

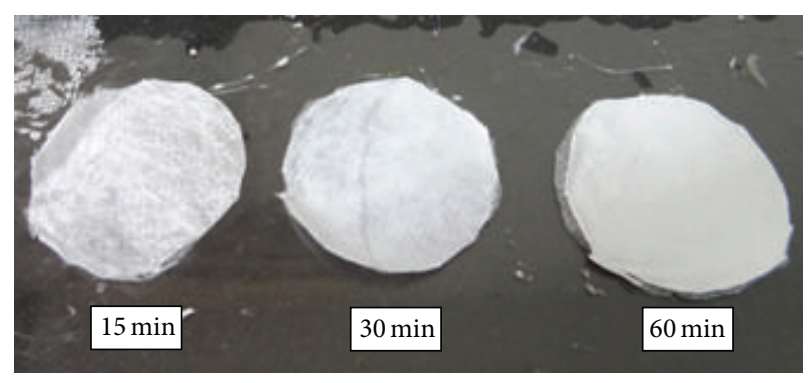

Figure 2: Nanomasks on non-woven fabrics.

\section{Results}

3.1. Morphology Observation. Figure 2 is the picture of nanofibers on the non-woven fabric. All the masks are white in color and homogeneously distributed on the non-woven fabric. The thickness of the electrospun fiber matts was at the rank of $15 \mathrm{~min}<30 \mathrm{~min}<60 \mathrm{~min}$.

According to the SEM images, the nanofibers of $15 \mathrm{~min}$ electrospinning were about $500-800 \mu \mathrm{m}$ in diameter with random orientation and high porosity (Figure 2 ). The interdistance among the nanofibers is about $1-3 \mu \mathrm{m}$. The nanofibers with 30 and 60 min electrospinning showed similar morphology to those of 15 min except for their higher thickness (data not shown).

3.2. Permeability Test. The permeability of the nanofiber masks was then compared with the commercial masks of disposable non-woven face mask, non-woven mask for operation room, Ito PM2.5, N95, and R95 (Figure 4). As listed in Table 2, the pressure drop of three nanofiber masks was $15 \mathrm{~min}<30 \mathrm{~min}<60 \mathrm{~min}$. Compared with the commercial masks, the disposable non-woven face mask showed the lowest pressure drop, while the R95 had the highest barrier to air permeability. The low pressure drop indicated the good permeability.

3.3. Intercept Rate Test of PM2.5 by Nanofiber Masks. Table 3 showed the PM2.5 rejection capability of each mask in the intercept rate test. The rejecting ratio was calculated by the rejected particles/total particles in air. All the three nanofiber masks performed a high rejected effect of $>90 \%$, at the rank of $60 \mathrm{~min}>30 \mathrm{~min}>15 \mathrm{~min}$. For the commercial available masks, the disposable non-woven face mask showed the poorest effect on PM2.5 rejection of $32.9 \%$, which could not match the requirement of daily use. By contrast, the R95 mask for medical use in preventing virus permeability had 
TABLE 2: The pressure drop statistics in permeability test.

\begin{tabular}{lccc}
\hline Masks & Import (KP) & Export (KP) & Pressure drop (KPa) \\
\hline Disposable non-woven face mask & 1.23 & 1.52 & $\Delta 0.29$ \\
Non-woven mask for operation room & 1.05 & 1.695 & $\Delta 0.645$ \\
Ito PM2.5 & 1.045 & 1.7 & $\Delta 0.655$ \\
N95 & 1.125 & 1.635 & $\Delta 0.51$ \\
R95 & 1.06 & 1.685 & $\Delta 0.625$ \\
Nanomask (15 minutes) & 1.43 & 1.84 & $\Delta 0.41$ \\
Nanomask (30 minutes) & 1.19 & 2.06 & $\Delta 0.87$ \\
Nanomask (60 minutes) & 0.915 & 2.023 & $\Delta 1.108$ \\
\hline
\end{tabular}

TABLE 3: PM2.5 rejection by selected masks.

\begin{tabular}{lcc}
\hline Sample & $\begin{array}{c}\text { Average particle } \\
\text { number }\end{array}$ & Rejection ratio \\
\hline $\begin{array}{l}\text { Indoor air (negative } \\
\text { Control) }\end{array}$ & $14452.9 \pm 320.6$ & - \\
\hline $\begin{array}{l}\text { Disposable } \\
\text { non-woven face mask }\end{array}$ & $9695.3 \pm 57.0$ & $32.9 \%$ \\
\hline $\begin{array}{l}\text { Non-woven mask for } \\
\text { operation room }\end{array}$ & $499.2 \pm 7.8$ & $96.5 \%$ \\
\hline $\begin{array}{l}\text { ITO PM2.5 } \\
\text { N95 }\end{array}$ & $2480.3 \pm 31.1$ & $82.8 \%$ \\
\hline R95 & $12.4 \pm 1.2$ & $94.9 \%$ \\
\hline $\begin{array}{l}\text { Nanomask (15 } \\
\text { minutes) }\end{array}$ & $476.7 \pm 8.5$ & $99.9 \%$ \\
\hline $\begin{array}{l}\text { Nanomask (30 } \\
\text { minutes) }\end{array}$ & $82.2 \pm 3.5$ & $96.9 \%$ \\
\hline $\begin{array}{l}\text { Nanomask (60 } \\
\text { minutes) }\end{array}$ & $0.3 \pm 0.1$ & $99.4 \%$ \\
\hline $\begin{array}{l}\text { Cellulose } \\
\text { microfiltration } \\
\text { membrane (positive } \\
\text { control) }\end{array}$ & $100.0 \%$ \\
\hline
\end{tabular}

an extremely high rejection of $99.9 \%$, which is the highest one among the selected masks in our study.

\section{Discussion}

In this study, a novel nanofiber mask was synthesized by electrospinning for preventing the PM2.5 from haze air. That nanofiber mask showed better performance than the commercial masks in both air permeability and PM2.5 rejection.

To make a clear comparison, the advantages and disadvantages of commercial masks have been summarized in Table 4. Most of these masks were made of non-woven fabric microfibers with large diameters of several micrometers [5]. The thin microfiber mask such as the disposable non-woven mask, though showed excellent air permeability, performed poor rejection on PM2.5 due to the insufficient thickness of fibers and larger interfiber space. In contrast, the thick microfiber masks of Ito PM2.5 and N95 improved the rejecting ratio of PM2.5 to $>80 \%$ which is enough for daily use. But they both had high resistance on air permeability which led to uncomfortable breathability in use. The R95 mask, which is commonly used in medical purpose, could well protect the doctors from virus infection. However, it was not suitable for preventing air pollution in daily use because of the extremely poor air permeability. The nanofiber mask with 15 min electrospinning had a high PM2.5 rejection of $90 \%$ and acceptable air permeability (Tables 2 and 3 ). Therefore, it is a good mask raw material for preventing haze air pollution.

The requirement on air permeability and PM2.5 rejection is a contradiction [6]. That means the high air permeability usually reduces the particle rejection of PM2.5 and vice versa. As shown in Figure 3, the nanofiber mask (15 min) displayed the largest difference between air permeability and PM2.5 rejection among these masks. We attribute that unique feature to the nanoscaled fiber size. At the same porosity, which indicates air permeability, the smaller fiber required higher quantity to achieve the same coverage as that of the bigger fiber. More fibers in the same area result in smaller interfiber space. From the SEM image in Figure 3, when the fiber scale is down to submicron, the interfiber space between the nanofibers is also reduced to micron scale, which is smaller than the PM2.5 size, consequently rejecting the PM2.5 passing efficiently.

\section{Conclusion}

This study synthesized a polysulfone nanofiber for mask filtration material by electrospinning. The nanofiber mask material was characterized by SEM, air permeability test, and PM2.5 trapping experiment. This nanofiber mask material can efficiently filter out the PM2.5 particles and simultaneously preserve a good breathability. In this regard, this nanofiber based material would be made into the comfortable and effective mask to prevent inhaling the harmful particles in haze air pollution. The nanofiber masks could be developed to commercial available masks in the future. 
TABLE 4: Comparison of different masks.

\begin{tabular}{|c|c|c|c|}
\hline Name & Material & The scope of use and effect & Problem \\
\hline \multirow[t]{2}{*}{ Medical masks } & Non-woven fabric & $\begin{array}{l}\text { For hospital outpatient, disposable, good } \\
\text { sanitary conditions }\end{array}$ & $\begin{array}{l}\text { Interception effect of fine } \\
\text { particles is poor }\end{array}$ \\
\hline & Blended material & $\begin{array}{l}\text { For the operation room, disposable, good } \\
\text { sanitary conditions }\end{array}$ & $\begin{array}{l}\text { Water vapor is poor, } \\
\text { respiratory resistance is } \\
\text { high }\end{array}$ \\
\hline ItoPM2.5 masks & Thickened non-woven fabric & Dedicated to filter PM2.5 & Respiratory resistance \\
\hline N95 masks & Thickened non-woven fabric & $\begin{array}{c}\text { Protection of professional occupation, } \\
\text { preventing a flow HINI and microbial } \\
\text { particles }\end{array}$ & $\begin{array}{l}\text { Respiratory resistance, } \\
\text { poor comfort }\end{array}$ \\
\hline R95 & Activated carbon & $\begin{array}{l}\text { Used for industrial dust and trace organic } \\
\text { gas entrapment }\end{array}$ & $\begin{array}{l}\text { Respiratory resistance, } \\
\text { poor comfort }\end{array}$ \\
\hline
\end{tabular}

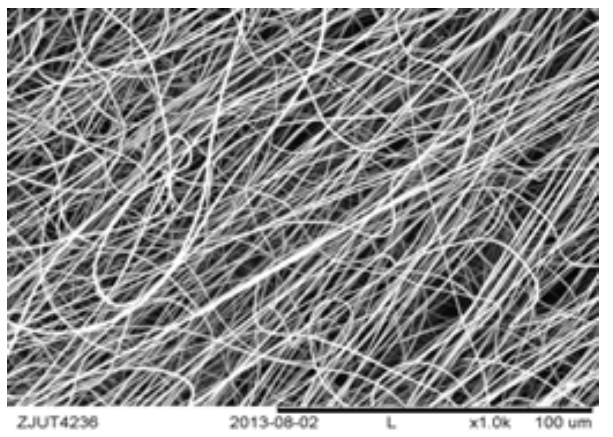

(a)

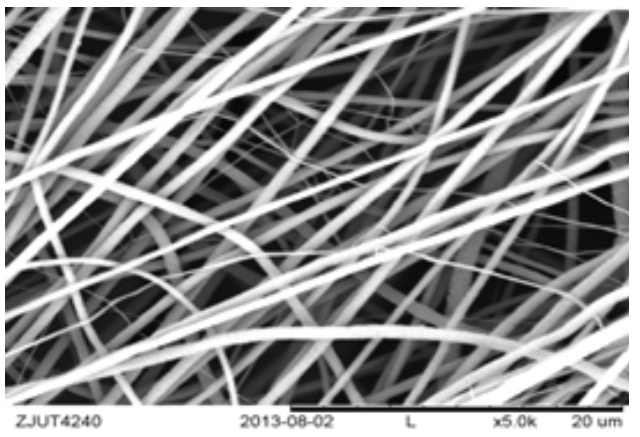

(b)

FIGURE 3: SEM images of masks after 15 min electrospinning. (a) $\times 1000$ and (b) $\times 5000$.

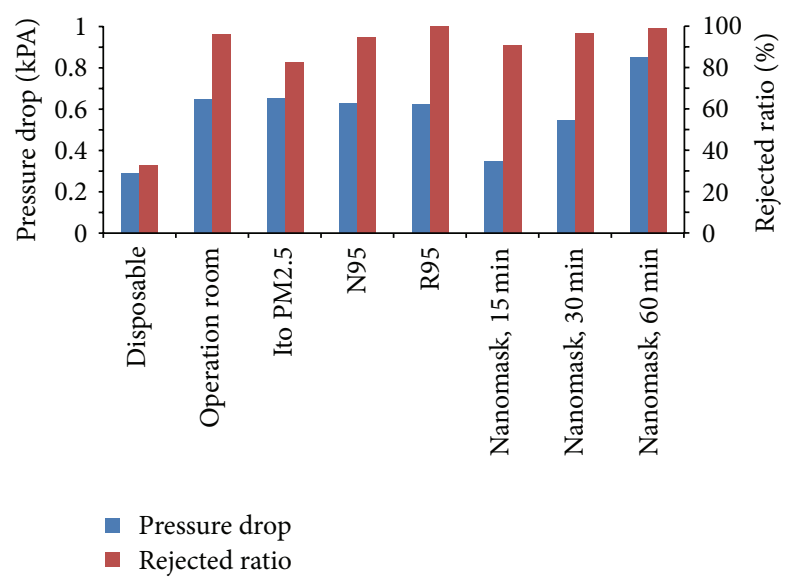

FIGURE 4: Permeability and intercept rate comprehensive comparison.

\section{Conflict of Interests}

The authors declare that there is no conflict of interests regarding the publication of this paper.

\section{Acknowledgements}

The authors gratefully acknowledge the financial support of this study by Beijing Nova Program (no. 2014033) and NSFC (National Natural Science Foundation of China, no. 21002006). They thank Chong Shen and Yuanyuan Dai in Zhejiang University for their help on mask fabrication and testing.

\section{References}

[1] K. Yoon, B. S. Hsiao, and B. Chu, "Functional nanofibers for environmental applications," Journal of Materials Chemistry, vol. 18, no. 44, pp. 5326-5334, 2008.

[2] A. Peters, D. W. Dockery, J. E. Muller, and M. A. Mittleman, "Increased particulate air pollution and the triggering of myocardial infarction," Circulation, vol. 103, no. 23, pp. 2810$2815,2001$.

[3] Y. Li, K. Xiao, J. Luo, J. Lee, S. Pan, and K. S. Lam, "A novel size-tunable nanocarrier system for targeted anticancer drug delivery," Journal of Controlled Release, vol. 144, no. 3, pp. 314323, 2010.

[4] H.-J. Jin, S. V. Fridrikh, G. C. Rutledge, and D. L. Kaplan, "Electrospinning Bombyx mori silk with poly (ethylene oxide)," Biomacromolecules, vol. 3, no. 6, pp. 1233-1239, 2002. 
[5] S. Chen, M. Kong, S. Wang, D. Kong, and Z. Gu, "The electrostatic spinning technology vs its application in the field of biomedicine," Chinese Journal of Biomedical Engineering, vol. 30, pp. 120-130, 2011.

[6] X. Qin and S. Wang, “The process principle, present situation and application prospect of electrostatic spinning of nano fibers," Donghua University High-Tech Fiber and Application, vol. 29, pp. 28-33, 2004. 

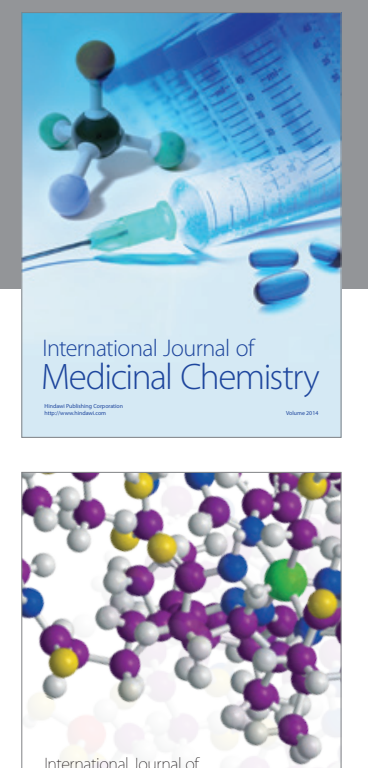

\section{Carbohydrate} Chemistry

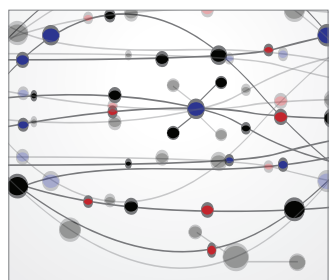

The Scientific World Journal
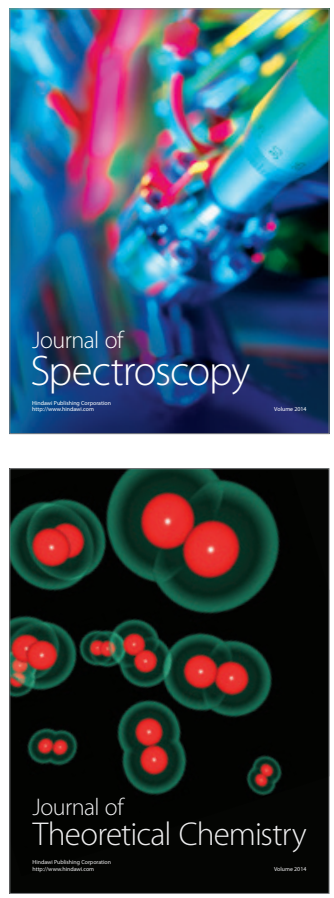
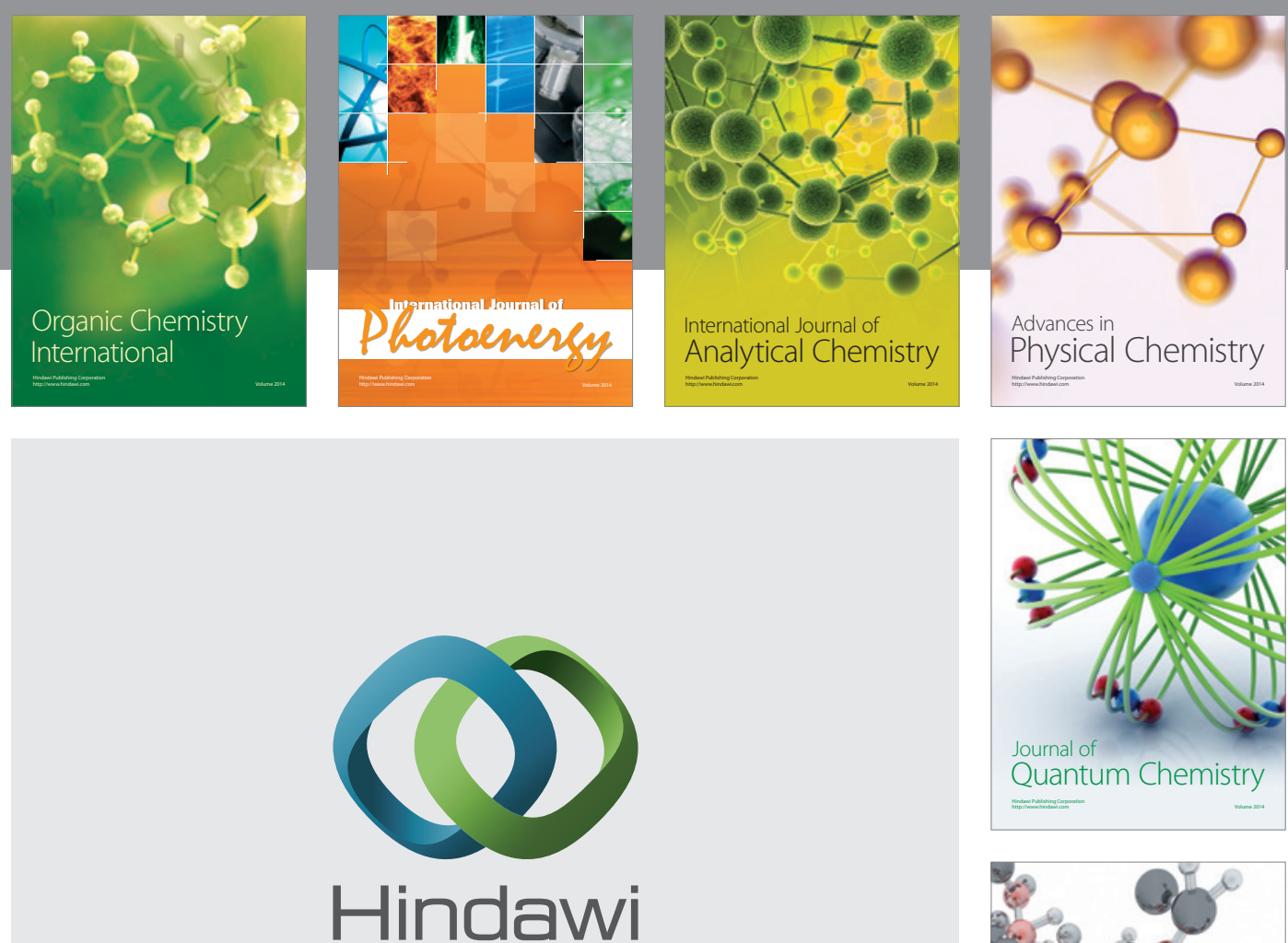

Submit your manuscripts at

http://www.hindawi.com

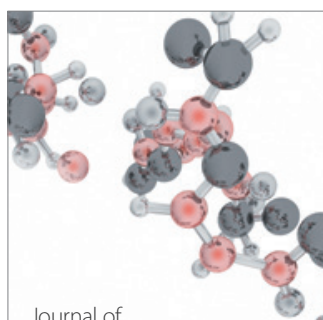

Analytical Methods

in Chemistry

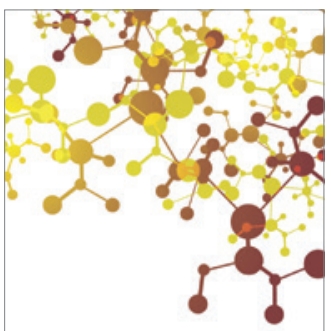

Journal of

Applied Chemistry

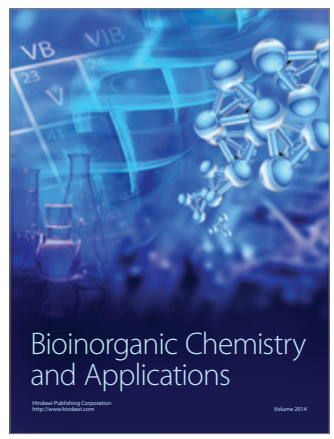

Inorganic Chemistry
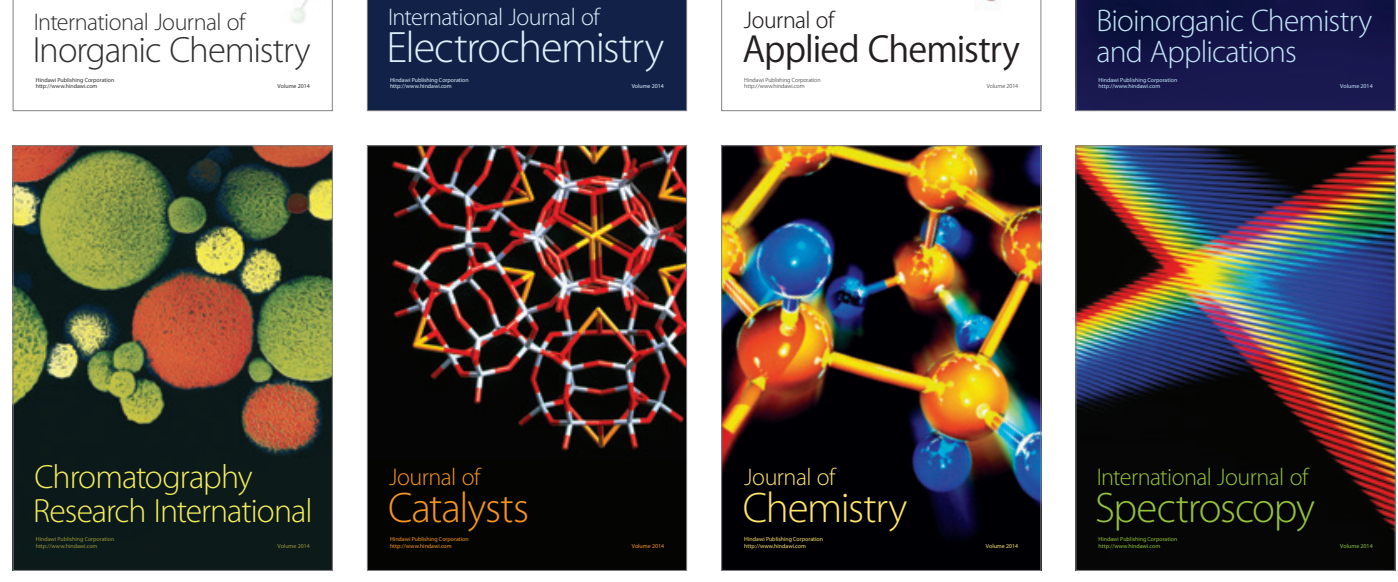